Supporting Information

\title{
Synthesis of Pachastrissamine from Phytosphingosine: A Comparison of Cyclic Sulfate vs Epoxide Intermediate in Cyclization
}

Taeho Lee, Sukjin Lee, Young Shin Kwak, Deukjoon Kim, and Sanghee Kim*

\section{Contents}

General Experimental Method

Full experimental procedures and analytical data of compounds

${ }^{1} \mathrm{H}$ NMR and ${ }^{13} \mathrm{C}$ NMR spectra of compound 4 S10-S11

${ }^{1} \mathrm{H}$ NMR and ${ }^{13} \mathrm{C}$ NMR spectra of compound $\mathbf{1}$

S12-S13

${ }^{1} \mathrm{H}$ NMR and ${ }^{13} \mathrm{C}$ NMR spectra of compound 7

S14-S15

${ }^{1} \mathrm{H}$ NMR and ${ }^{13} \mathrm{C}$ NMR spectra of compound 9

S16-S17

${ }^{1} \mathrm{H}$ NMR and ${ }^{13} \mathrm{C}$ NMR spectra of compound $\mathbf{1 0}$

S18-S19

${ }^{1} \mathrm{H}$ NMR and ${ }^{13} \mathrm{C}$ NMR spectra of compound $\mathbf{1 1}$

S20-S21

${ }^{1} \mathrm{H}$ NMR and ${ }^{13} \mathrm{C}$ NMR spectra of compound $\mathbf{1 2}$

S22-S23 
General. All chemicals were reagent grade and used as purchased. All reactions were performed under an inert atmosphere of dry argon or nitrogen using distilled dry solvents. Reactions were monitored by TLC analysis using silica gel 60 F-254 TLC plates. Melting points are uncorrected. Flash column chromatography was carried out on silica gel (230-400 mesh). Optical rotations were measured using sodium light (D line $589.3 \mathrm{~nm}) .{ }^{1} \mathrm{H}$ NMR and ${ }^{13} \mathrm{C}$ NMR spectra were recorded in $\delta$ units relative to deuterated solvent as internal reference at 300 and $75 \mathrm{MHz}$, respectively. IR spectra were measured on a Fourier Transform Infrared spectrometer. High resolution mass spectra (HRMS) were recorded using fast atom bombardment (FAB) or chemical ionization (CI). 


\section{(2S,3S,4S)-4-Azido-2-tetradecyl-tetrahydrofuran-3-ol (4)}

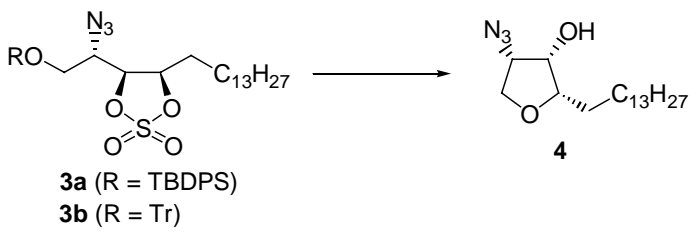

From 3a: To a solution of cyclic sulfate $\mathbf{3 a}^{5}(258 \mathrm{mg}, 0.400 \mathrm{mmol})$ in THF $(8 \mathrm{~mL})$ was added TBAF $(0.44 \mathrm{~mL}, 0.440 \mathrm{mmol}, 1.0 \mathrm{M}$ solution in THF) at room temperature. The reaction mixture was stirred for $1 \mathrm{~h}$ at room temperature, and to it were added concentrated $\mathrm{H}_{2} \mathrm{SO}_{4}(34 \mu \mathrm{L}), \mathrm{H}_{2} \mathrm{O}(42 \mu \mathrm{L})$ and THF $(524 \mu \mathrm{L})$. The mixture was stirred for $1 \mathrm{~h}$ at room temperature and then diluted with EtOAc. It was washed with saturated aqueous $\mathrm{NaHCO}_{3}$ solution and brine. The organic layer was dried over $\mathrm{Na}_{2} \mathrm{SO}_{4}$, concentrated, and purified by silica gel column chromatography (hexane/EtOAc, 5:1) to give $4(112 \mathrm{mg}, 86 \%)$ as a white solid.

From 3b: To a solution of cyclic sulfate $\mathbf{3 b ^ { 5 }}$ (136 mg, $\left.0.210 \mathrm{mmol}\right)$ in $\mathrm{CH}_{3} \mathrm{CN}(3 \mathrm{~mL})$ was added $\mathrm{H}_{2} \mathrm{O}(0.20 \mathrm{~mL}, 11.1 \mathrm{mmol}, 50$ equvi) at room temperature. The reaction mixture was heated to reflux for $6 \mathrm{~h}$, and then concentrated. The residue was purified by silica gel column chromatography (hexane/EtOAc, 5:1) to give $4(50 \mathrm{mg}, 74 \%)$ as a white solid: mp 99.4-100.1 ${ }^{\circ} \mathrm{C} ;[\alpha]^{24}{ }_{\mathrm{D}}+16.7$ (c 1.0, $\left.\mathrm{CHCl}_{3}\right) ;{ }^{1} \mathrm{H}$ NMR $\left(\mathrm{CDCl}_{3}, 300\right.$ MHz) $\delta 0.88(\mathrm{t}, J=6.6 \mathrm{~Hz}, 3 \mathrm{H}), 1.25-1.43(\mathrm{~m}, 24 \mathrm{H}), 1.63(\mathrm{~m}, 2 \mathrm{H}), 2.10$ (br s. $1 \mathrm{H}), 3.76$ (ddd, $J=3.6,6.9,6.9 \mathrm{~Hz}, 1 \mathrm{H}), 3.85(\mathrm{dd}, J=6.6,9.0 \mathrm{~Hz}, 1 \mathrm{H}), 3.97(\mathrm{dd}, J=7.2,9.0 \mathrm{~Hz}$, $1 \mathrm{H}), 4.11(\mathrm{ddd}, J=4.8,6.9,6.9 \mathrm{~Hz}, 1 \mathrm{H}), 4.20(\mathrm{dd}, J=3.9,4.5 \mathrm{~Hz}, 1 \mathrm{H}) ;{ }^{13} \mathrm{C} \mathrm{NMR}$ $\left(\mathrm{CDCl}_{3}, 75 \mathrm{MHz}\right) \delta 14.1,22.7,26.0,28.8,29.3,29.51,29.55,29.65,31.9,63.7,68.4$, 72.5, 82.1; IR $\left(\mathrm{CH}_{3} \mathrm{Cl}\right) v_{\max } 3329,2917,2849,2105,1468\left(\mathrm{~cm}^{-1}\right)$; HRMS (CI) calcd for $\mathrm{C}_{18} \mathrm{H}_{36} \mathrm{O}_{2} \mathrm{~N}_{3}\left([\mathrm{M}+\mathrm{H}]^{+}\right)$326.2808, found 326.2805. 


\section{(2S,3S,4S)-4-Amino-2-tetradecyl-tetrahydrofuran-3-ol (pachastrissamine, 1)}

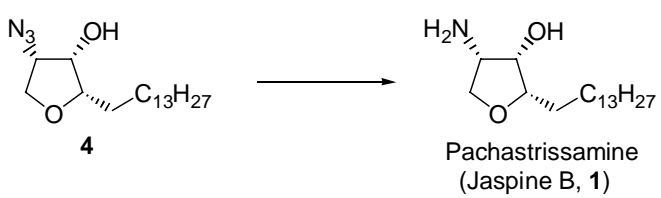

A solution of $4(88 \mathrm{mg}, 0.27 \mathrm{mmol})$ in $\mathrm{MeOH}(4 \mathrm{~mL})$ and $\mathrm{CH}_{2} \mathrm{Cl}_{2}(2 \mathrm{~mL})$ was charged with $10 \% \mathrm{Pd} / \mathrm{C}$ (45 mg, $50 \mathrm{wt} \%$ ). The mixture was stirred for $3 \mathrm{~h}$ under a balloon filled with $\mathrm{H}_{2}$ at room temperature. It was diluted with $\mathrm{CH}_{2} \mathrm{Cl}_{2} / \mathrm{MeOH}$ and filtered through a pad of Celite. The solvent was removed, and the residue was purified by silica gel column chromatography $\left(\mathrm{CH}_{2} \mathrm{Cl}_{2} / \mathrm{MeOH}, 9: 1,1 \% \mathrm{NH}_{4} \mathrm{OH}\right)$ to give pachastrissamine (1) $\left(74 \mathrm{mg}, 93 \%\right.$ ) as a white solid: mp 96.6-97.2 ${ }^{\circ} \mathrm{C}\left(\right.$ lit. ${ }^{3 \mathrm{c}} \mathrm{mp} 70-72{ }^{\circ} \mathrm{C}$, lit. $\left.{ }^{3 e} \mathrm{mp} 89-91{ }^{\circ} \mathrm{C}\right) ;[\alpha]^{24}+76.0\left(c 0.2, \mathrm{CHCl}_{3}\right),[\alpha]^{23}{ }_{\mathrm{D}}+19.7(c 0.5, \mathrm{MeOH}),\left(\right.$ lit. $^{1}[\alpha]_{\mathrm{D}}$ $+18(c 0.1, \mathrm{EtOH})$, lit. $^{2}[\alpha]^{20}{ }_{\mathrm{D}}+7\left(c 0.1, \mathrm{CHCl}_{3}\right)$, lit. $^{3 \mathrm{a}}[\alpha]_{\mathrm{D}}+9\left(c 1.5, \mathrm{CHCl}_{3}\right)$, lit. $^{3 \mathrm{~b}}$ $[\alpha]_{D}^{25}+7\left(c 0.2, \mathrm{CHCl}_{3}\right)$, lit. $\left.^{3 \mathrm{c}}[\alpha]_{\mathrm{D}}^{25}+7.0(c) .1, \mathrm{CHCl}_{3}\right)$, lit. $^{3 \mathrm{e}}[\alpha]_{\mathrm{D}}^{22}+4.8$ (c 1.0, $\mathrm{MeOH})$ ); ${ }^{1} \mathrm{H} \mathrm{NMR}\left(\mathrm{CDCl}_{3}, 300 \mathrm{MHz}\right) \delta 0.87(\mathrm{t}, J=6.6 \mathrm{~Hz}, 3 \mathrm{H}), 1.24-1.43(\mathrm{~m}, 24 \mathrm{H})$, $1.65(\mathrm{~m}, 2 \mathrm{H}), 2.09$ (br s, 3H), $3.50(\mathrm{dd} J=6.9,8.1 \mathrm{~Hz}, 1 \mathrm{H}), 3.64(\mathrm{dt}, J=5.1,6.9 \mathrm{~Hz}$, 1H), 3.73 (app. dt, $J=3.3,6.9 \mathrm{~Hz}, 1 \mathrm{H}), 3.86(\mathrm{dd}, J=3.6,4.8 \mathrm{~Hz}, 1 \mathrm{H}), 3.92(\mathrm{dd}, J=7.2$, 8.1 Hz, 1H); ${ }^{13} \mathrm{C} \mathrm{NMR}\left(\mathrm{CDCl}_{3}, 75 \mathrm{MHz}\right) \delta 14.1,22.7,26.3,29.3,29.4,29.57,29.59$, 29.7, 29.8, 31.9, 54.3, 71.8, 72.3, 83.2; IR $\left(\mathrm{CH}_{3} \mathrm{Cl}\right) v_{\max } 3351,3056,2907,2851,1477$ $\left(\mathrm{cm}^{-1}\right)$; HRMS (FAB) calcd for $\mathrm{C}_{18} \mathrm{H}_{38} \mathrm{O}_{2} \mathrm{~N}\left([\mathrm{M}+\mathrm{H}]^{+}\right)$300.2903, found 300.2898.

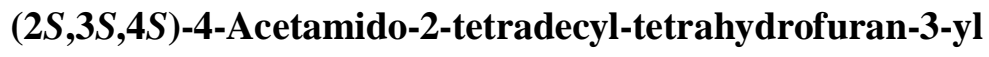
acetate(pachastrissamine diacetate) 


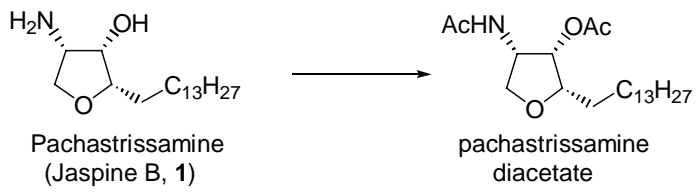

To a solution of pachastrissamine (1) $(33 \mathrm{mg}, 0.11 \mathrm{mmol})$ in $\mathrm{CH}_{2} \mathrm{Cl}_{2}(4 \mathrm{~mL})$ were added acetic anhydride $(50 \mu \mathrm{L}, 0.53 \mathrm{mmol})$ and triethylamine $(80 \mu \mathrm{L}, 0.57 \mathrm{mmol})$ at 0 ${ }^{\circ} \mathrm{C}$. After $6 \mathrm{~h}$, this reaction mixture was poured into water and extracted with $\mathrm{CH}_{2} \mathrm{Cl}_{2}$ twice. The combined organic layers were washed with brine, dried over $\mathrm{MgSO}_{4}$ and concentrated. The residue was purified by silica gel column chromatography $\left(\mathrm{CH}_{2} \mathrm{Cl}_{2} / \mathrm{EtOAc}, 2: 1\right)$ to give pachastrissamine diacetate $(39 \mathrm{mg}, 91 \%)$ as a white solid; mp 109.7-110.4 ${ }^{\circ} \mathrm{C}\left(\right.$ lit. $\left.^{3 \mathrm{e}} \mathrm{mp} 95-98{ }^{\circ} \mathrm{C}\right) ;[\alpha]^{24}{ }_{\mathrm{D}}-18.5\left(c 0.7, \mathrm{CHCl}_{3}\right)\left(\right.$ lit. $^{3 \mathrm{a}}[\alpha]_{\mathrm{D}}-28.4(c$ 1, $\left.\mathrm{CHCl}_{3}\right)$, lit. $\left.^{3 \mathrm{e}}[\alpha]^{22}{ }_{\mathrm{D}}-22.6\left(c 1.0, \mathrm{CDCl}_{3}\right)\right) ;{ }^{1} \mathrm{H} \mathrm{NMR}\left(\mathrm{CDCl}_{3}, 300 \mathrm{MHz}\right) \delta 0.87(\mathrm{t}, J=$ $6.6 \mathrm{~Hz}, 3 \mathrm{H}), 1.25-1.47(\mathrm{~m}, 26 \mathrm{H}), 1.98(\mathrm{~s}, 3 \mathrm{H}), 2.16(\mathrm{~s}, 3 \mathrm{H}), 3.59$ (t, $J=8.1 \mathrm{~Hz}, 1 \mathrm{H})$, $3.90(\mathrm{~m}, 1 \mathrm{H}), 4.07(\mathrm{t}, J=8.4 \mathrm{~Hz}, 1 \mathrm{H}), 4.81$ (dddd, $J=5.4,8.1,8.1,8.1 \mathrm{~Hz}, 1 \mathrm{H}), 5.38$ $(\mathrm{dd}, J=3.3,5.4 \mathrm{~Hz}, 1 \mathrm{H}), 5.60($ br d, $J=8.1 \mathrm{~Hz}, 1 \mathrm{H}) ;{ }^{13} \mathrm{C} \mathrm{NMR}\left(\mathrm{CDCl}_{3}, 75 \mathrm{MHz}\right) \delta$ $14.1,20.7,22.7,23.1,26.0,29.27,29.32,29.4,29.51,29.55,29.62,29.65,31.9,51.3$, 69.9, 73.5, 81.2, 169.8, 169.9; IR $\left(\mathrm{CHCl}_{3}\right) v_{\max } 2919,2853,1739,1643\left(\mathrm{~cm}^{-1}\right) ; \mathrm{HRMS}$ (FAB) calcd for $\mathrm{C}_{22} \mathrm{H}_{42} \mathrm{O}_{4} \mathrm{~N}\left([\mathrm{M}+\mathrm{H}]^{+}\right)$384.3114, found 384.3107 .

\section{$\{(S)$-2-Azido-2-[(2S,3R)-3-tetradecyloxiran-2-yl]ethoxy $\}$-tert-butyldiphenylsilane}

(7)

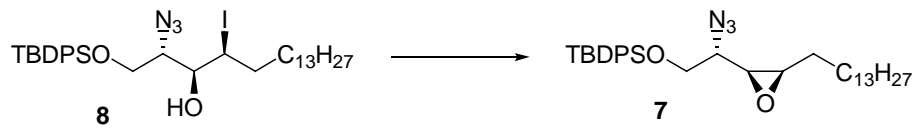

To a solution of $\mathbf{8}^{5}$ (102 $\left.\mathrm{mg}, 0.147 \mathrm{mmol}\right)$ in $\mathrm{MeOH}(4 \mathrm{~mL})$ was added $\mathrm{K}_{2} \mathrm{CO}_{3}(41 \mathrm{mg}$, $0.30 \mathrm{mmol}$ ). This reaction mixture was stirred at room temperature for $2 \mathrm{~h}$, and then 
diluted with $\mathrm{CH}_{2} \mathrm{Cl}_{2}$. It was washed with brine and dried over $\mathrm{MgSO}_{4}$. The solvent was removed, and the residue was purified by flash silica gel column chromatography (hexane/EtOAc, $15: 1)$ to give epoxide $7(83 \mathrm{mg}, 99 \%)$ as a colorless oil: $[\alpha]^{24}+7.1(c$ 1.0, $\left.\mathrm{CHCl}_{3}\right) ;{ }^{1} \mathrm{H} \mathrm{NMR}\left(\mathrm{CDCl}_{3}, 300 \mathrm{MHz}\right) \delta 0.89(\mathrm{t}, J=6.6 \mathrm{~Hz}, 3 \mathrm{H}), 1.10(\mathrm{~s}, 9 \mathrm{H}), 1.28-$ $1.60(\mathrm{~m}, 26 \mathrm{H}), 2.99-3.03(\mathrm{~m}, 2 \mathrm{H}), 3.19(\mathrm{ddd}, J=3.0,6.3,8.7 \mathrm{~Hz}, 1 \mathrm{H}), 3.89(\mathrm{dd}, J=6.3$, $11.1 \mathrm{~Hz}, 1 \mathrm{H}), 3.98(\mathrm{dd}, J=3.0,10.5 \mathrm{~Hz}, 1 \mathrm{H}), 7.38-7.48(\mathrm{~m}, 6 \mathrm{H}), 7.70-7.73(\mathrm{~m}, 4 \mathrm{H}) ;{ }^{13} \mathrm{C}$ NMR $\left(\mathrm{CDCl}_{3}, 75 \mathrm{MHz}\right) \delta 14.1,19.1,22.7,26.4,26.7,27.9,29.3,29.41,29.47,29.51$, $29.7,31.9,54.1,57.0,60.9,65.3,127.8,129.8,132.7,132.9,135.57,135.59$; IR $\left(\mathrm{CH}_{3} \mathrm{Cl}\right) v_{\max } 2924,2841,2106,1425\left(\mathrm{~cm}^{-1}\right)$; HRMS (CI) calcd for $\mathrm{C}_{34} \mathrm{H}_{54} \mathrm{O}_{2} \mathrm{~N}_{3} \mathrm{Si}([\mathrm{M}+$ $\left.\mathrm{H}]^{+}\right)$564.3985, found 564.3981 .

\section{(S)-2-Azido-2-[(2S,3R)-3-tetradecyloxiran-2-yl]ethanol (9)}

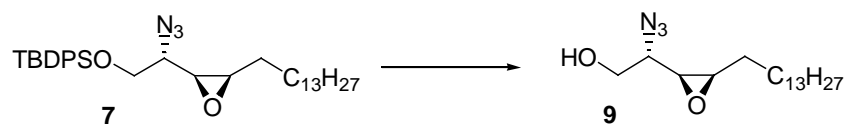

To a solution of epoxide 7 (123 mg, $0.218 \mathrm{mmol})$ in THF (5 mL) was added TBAF $(0.3 \mathrm{~mL}, 0.30 \mathrm{mmol}, 1.0 \mathrm{M}$ solution in THF) at room temperature. After being stirred for $2 \mathrm{~h}$ at room temperature, the reaction mixture was diluted with EtOAc and washed with brine. The organic layer was dried over $\mathrm{Na}_{2} \mathrm{SO}_{4}$ and concentrated. The crude product was purified by silica gel column chromatography (hexane/EtOAc, 5:1) to give epoxy alcohol 9 (70 mg, 99\%) as a white solid: $\mathrm{mp} 67.1-67.4{ }^{\circ} \mathrm{C} ;[\alpha]^{24} \mathrm{D}+34(c$ 1.1, $\left.\mathrm{CHCl}_{3}\right) ;{ }^{1} \mathrm{H} \mathrm{NMR}\left(\mathrm{CDCl}_{3}, 300 \mathrm{MHz}\right) \delta 0.88(\mathrm{t}, J=6.6 \mathrm{~Hz}, 3 \mathrm{H}), 1.26-1.68(\mathrm{~m}, 26 \mathrm{H})$, 1.91 (br s, 1H), $3.02(\mathrm{dd}, J=3.9,8.7 \mathrm{~Hz}, 1 \mathrm{H}), 3.08(\mathrm{ddd}, J=3.9,4.2,6.3 \mathrm{~Hz}, 1 \mathrm{H}), 3.25$ $(\mathrm{ddd}, J=3.9,6.3,8.7 \mathrm{~Hz}, 1 \mathrm{H}), 3.79(\mathrm{dd}, J=6.3,11.4 \mathrm{~Hz}, 1 \mathrm{H}), 3.93(\mathrm{dd}, J=3.9,11.4$ $\mathrm{Hz}, 1 \mathrm{H}) ;{ }^{13} \mathrm{C} \mathrm{NMR}\left(\mathrm{CDCl}_{3}, 75 \mathrm{MHz}\right) \delta 14.1,22.6,26.4,28.0,29.3,29.40,29.44,29.5$, 
29.57, 29.61, 29.63, 29.64, 31.9, 54.7, 57.2, 60.9, 63.6; IR $\left(\mathrm{CH}_{3} \mathrm{Cl}\right) v_{\max } 3285,3177$, 2917, 2851, 2141, 2095, $1472\left(\mathrm{~cm}^{-1}\right)$; HRMS (CI) calcd for $\mathrm{C}_{18} \mathrm{H}_{36} \mathrm{O}_{2} \mathrm{~N}_{3}\left([\mathrm{M}+\mathrm{H}]^{+}\right)$ 326.2808, found 326.2806 .

\section{$(2 R, 3 S, 4 S)$-4-Azido-2-tetradecyl-tetrahydrofuran-3-ol (10)}

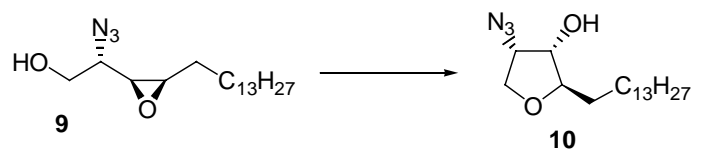

To a solution of epoxy alcohol $9(43 \mathrm{mg}, 0.132 \mathrm{mmol})$ in toluene $(4 \mathrm{~mL})$ was added $\mathrm{TsOH}(2 \mathrm{mg}, 10 \mu \mathrm{mol}, 0.1$ equiv). The reaction mixture was heated to reflux for $12 \mathrm{~h}$ and cooled to room temperature. It was diluted with $\mathrm{CH}_{2} \mathrm{Cl}_{2}$ and washed with brine. The organic layer was dried over $\mathrm{Na}_{2} \mathrm{SO}_{4}$ and concentrated. The crude product was purified by silica gel column chromatography (hexane/EtOAc, 5:1) to give $\mathbf{1 0}(34 \mathrm{mg}, 79 \%)$ as a white solid: $\mathrm{mp}$ 64.7-65.8 ${ }^{\circ} \mathrm{C} ;[\alpha]^{24}{ }_{\mathrm{D}}+29.9\left(\mathrm{c} 1.0, \mathrm{CHCl}_{3}\right) ;{ }^{1} \mathrm{H} \mathrm{NMR}\left(\mathrm{CDCl}_{3}, 300 \mathrm{MHz}\right)$ $\delta 0.88(\mathrm{t}, J=6.6 \mathrm{~Hz}, 3 \mathrm{H}), 1.25-1.69(\mathrm{~m}, 26 \mathrm{H}), 2.24(\mathrm{br} \mathrm{d}, J=7.2 \mathrm{~Hz}, 1 \mathrm{H}), 3.58-3.65(\mathrm{~m}$, 1H), 3.80 (dd, $J=4.5,9.3 \mathrm{~Hz}, 1 \mathrm{H}$ ), 3.89 (br app. q, $J=6.3 \mathrm{~Hz}, 1 \mathrm{H}), 4.03$ (ddd, $J=4.8$, 5.4, $6.0 \mathrm{~Hz}, 1 \mathrm{H}), 4.13(\mathrm{dd}, J=5.7,9.6 \mathrm{~Hz}, 1 \mathrm{H}) ;{ }^{13} \mathrm{C} \mathrm{NMR}\left(\mathrm{CDCl}_{3}, 75 \mathrm{MHz}\right) \delta 14.1$, $22.7,25.7,29.3,29.50,29.55,29.58,29.6,29.7,31.9,33.2,63.3,69.3,76.2,82.9$; IR $\left(\mathrm{CH}_{3} \mathrm{Cl}\right) v_{\max } 3293,2920,2849,2108,1468\left(\mathrm{~cm}^{-1}\right)$; HRMS (CI) calcd for $\mathrm{C}_{18} \mathrm{H}_{36} \mathrm{O}_{2} \mathrm{~N}_{3}$ $\left([\mathrm{M}+\mathrm{H}]^{+}\right)$326.2808, found 326.2806.

(2S,3S,4S)-2-Azido-1,3-dihydroxyoctadecan-4-yl 4-methylbenzenesulfonate (11)

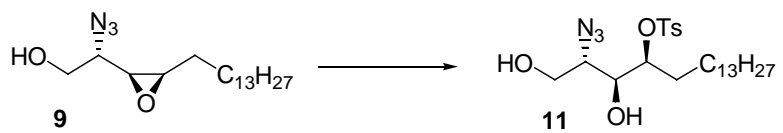


To a solution of epoxy alcohol 9 (42 $\mathrm{mg}, 0.129 \mathrm{mmol})$ in $\mathrm{CH}_{2} \mathrm{Cl}_{2}(4 \mathrm{~mL})$ was added TsOH (30 mg, $0.158 \mathrm{mmol}, 1.2$ equiv). The reaction mixture was stirred at room temperature for $8 \mathrm{~h}$, and then diluted with $\mathrm{CH}_{2} \mathrm{Cl}_{2}$. It was washed with brine, dried over $\mathrm{Na}_{2} \mathrm{SO}_{4}$ and concentrated. The residue was purified by silica gel column chromatography (hexane/EtOAc, 5:1) to give $\mathbf{1 0}(20 \mathrm{mg}, 48 \%)$ and the unstable hydroxyl tosylate $11(21 \mathrm{mg}, 32 \%)$ as a colorless oil: ${ }^{1} \mathrm{H} \mathrm{NMR}\left(\mathrm{CDCl}_{3}, 300 \mathrm{MHz}\right) \delta$ $0.88(\mathrm{t}, J=6.6 \mathrm{~Hz}, 3 \mathrm{H}), 1.26-1.78(\mathrm{~m}, 26 \mathrm{H}), 2.45(\mathrm{~s}, 3 \mathrm{H}), 3.46-3.56(\mathrm{~m}, 2 \mathrm{H}), 3.92(\mathrm{dd}, J$ $=4.2,11.7 \mathrm{~Hz}, 1 \mathrm{H}), 4.00(\mathrm{dd}, J=3.6,11.7 \mathrm{~Hz}, 1 \mathrm{H}), 4.82(\mathrm{t}, J=6.6 \mathrm{~Hz}, 1 \mathrm{H}), 7.36(\mathrm{~d}, J$ $=7.8 \mathrm{~Hz}, 1 \mathrm{H}), 7.83(\mathrm{dt}, J=1.5,8.4 \mathrm{~Hz}, 1 \mathrm{H}) ;{ }^{13} \mathrm{C} \mathrm{NMR}\left(\mathrm{CDCl}_{3}, 75 \mathrm{MHz}\right) \delta 14.1,21.6$, 22.7, 25.0, 25.7, 29.1, 29.3, 29.4, 29.7, 31.1, 31.9, 62.5, 62.9, 71.1, 82.3, 127.8, 129.9, 133.7, 145.2.

(2R,3S,4S)-4-Amino-2-tetradecyl-tetrahydrofuran-3-ol (epi-pachastrissamine, 12)

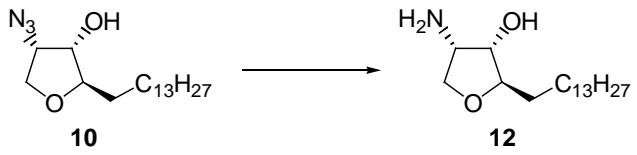

A solution of $10(52 \mathrm{mg}, 0.16 \mathrm{mmol})$ in $\mathrm{MeOH}(4 \mathrm{~mL})$ and $\mathrm{CH}_{2} \mathrm{Cl}_{2}(2 \mathrm{~mL})$ was charged with $10 \% \mathrm{Pd} / \mathrm{C}(26 \mathrm{mg}, 50 \mathrm{wt} \%)$. The mixture was stirred for $3 \mathrm{~h}$ under a balloon filled with $\mathrm{H}_{2}$ at room temperature. It was diluted with $\mathrm{CH}_{2} \mathrm{Cl}_{2} / \mathrm{MeOH}$ and filtered through a pad of Celite. The solvent was removed, and the residue was purified by silica gel column chromatography $\left(\mathrm{CH}_{2} \mathrm{Cl}_{2} / \mathrm{MeOH}, 9: 1,1 \% \mathrm{NH}_{4} \mathrm{OH}\right)$ to give epipachastrissamine (12) (45 mg, 94\%) as a white solid: solid: $\mathrm{mp} 103.9-104.9{ }^{\circ} \mathrm{C}\left(\right.$ lit. $^{3 \mathrm{e}} \mathrm{mp}$ 85-87 ${ }^{\circ} \mathrm{C}$, lit. $\left.{ }^{16} \mathrm{mp} 103.5-104.2{ }^{\circ} \mathrm{C}\right) ;[\alpha]^{23} \mathrm{D}+23.2\left(c\right.$ 1.0, MeOH) $\left(\right.$ lit. $^{3 \mathrm{e}}[\alpha]^{22} \mathrm{D}+15.0(c$ 1.0, $\mathrm{MeOH})$, lit. $\left.^{16}[\alpha]^{23}{ }_{\mathrm{D}}+14.8(c 0.2, \mathrm{EtOH})\right) ;{ }^{1} \mathrm{H}$ NMR $\left(\mathrm{CDCl}_{3}, 300 \mathrm{MHz}\right) \delta 0.87(\mathrm{t}, J$ $=6.6 \mathrm{~Hz}, 3 \mathrm{H}), 1.24-1.60(\mathrm{~m}, 26 \mathrm{H}), 2.13(\mathrm{br} \mathrm{s}, 3 \mathrm{H}), 3.39(\mathrm{dd}, J=6.9,8.4 \mathrm{~Hz}, 1 \mathrm{H}), 3.45$ 
(m, 1H), $3.60(\mathrm{dd}, J=5.1,10.8 \mathrm{~Hz}, 1 \mathrm{H}), 3.62(\mathrm{~m}, 1 \mathrm{H}), 4.11(\mathrm{dd}, J=6.0,8.4 \mathrm{~Hz}, 1 \mathrm{H})$; ${ }^{13} \mathrm{C} \mathrm{NMR}\left(\mathrm{CDCl}_{3}, 75 \mathrm{MHz}\right) \delta 14.1,22.7,25.9,29.4,29.5,29.6,29.7,31.9,33.7,52.7$, 73.1, 74.8, 85.2; IR $\left(\mathrm{CH}_{3} \mathrm{Cl}\right) v_{\max } 3420,2917,2851,1474\left(\mathrm{~cm}^{-1}\right)$; HRMS (FAB) calcd for $\mathrm{C}_{18} \mathrm{H}_{38} \mathrm{O}_{2} \mathrm{~N}\left([\mathrm{M}+\mathrm{H}]^{+}\right)$300.2903, found 300.2903. 


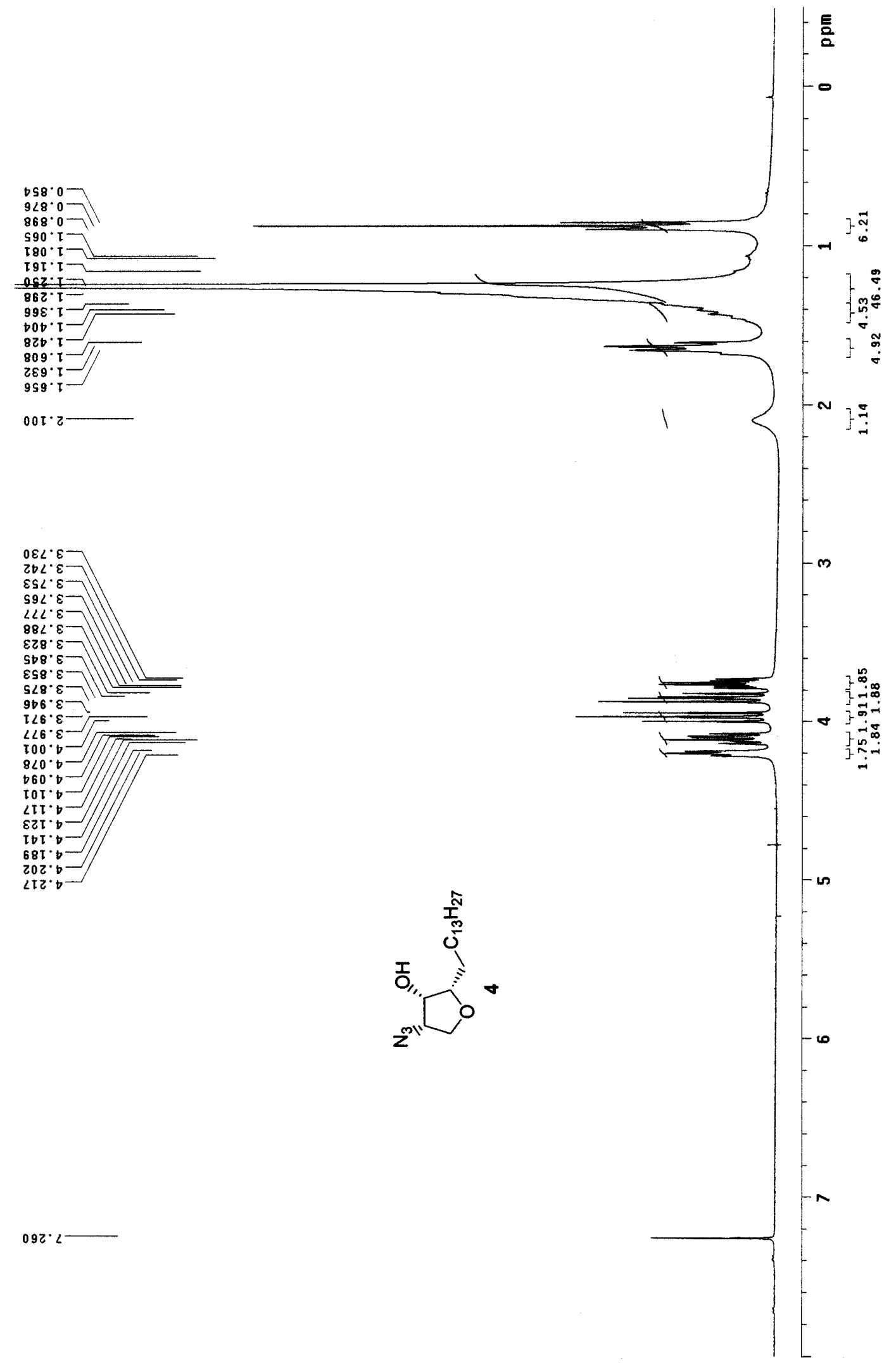



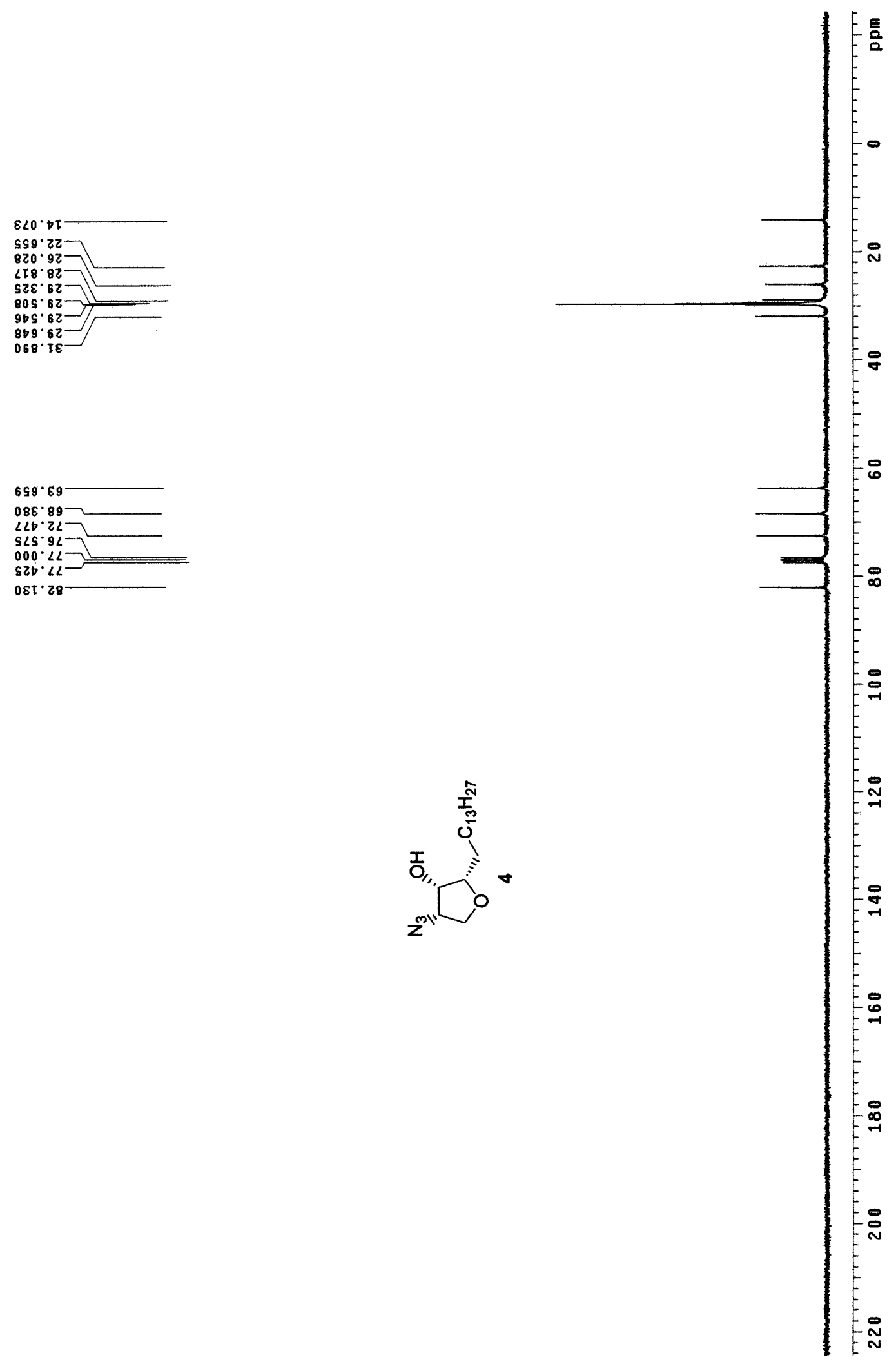


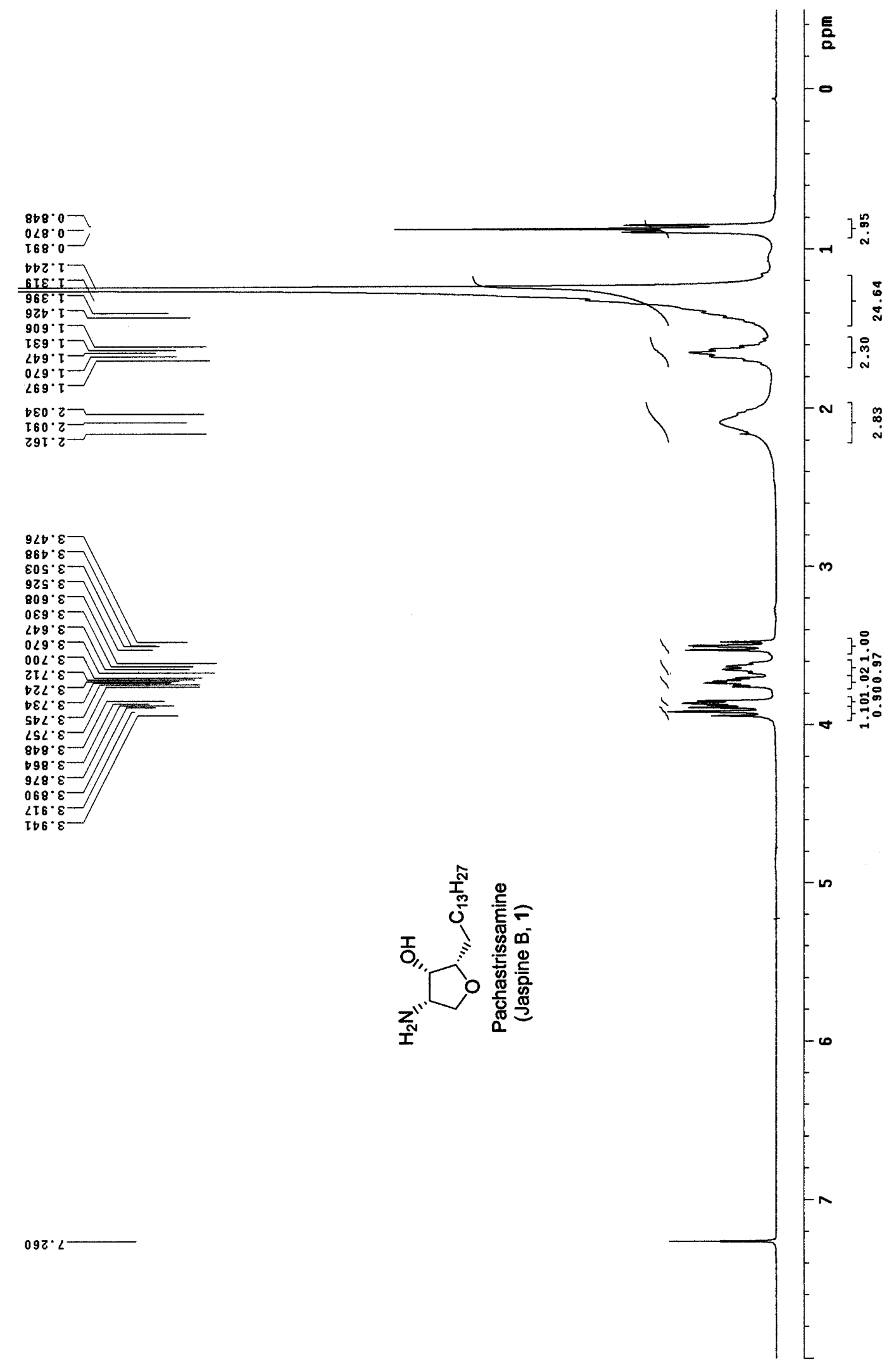




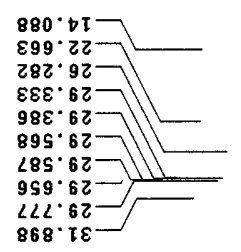

$62 \varepsilon \cdot \nabla s$

$\varepsilon S L \cdot \tau L$

$\checkmark \supset \varepsilon \cdot 2 L$

619.2

$000 . \angle L-\square$

$S 2 t \cdot \angle L$

โ8โ. 88

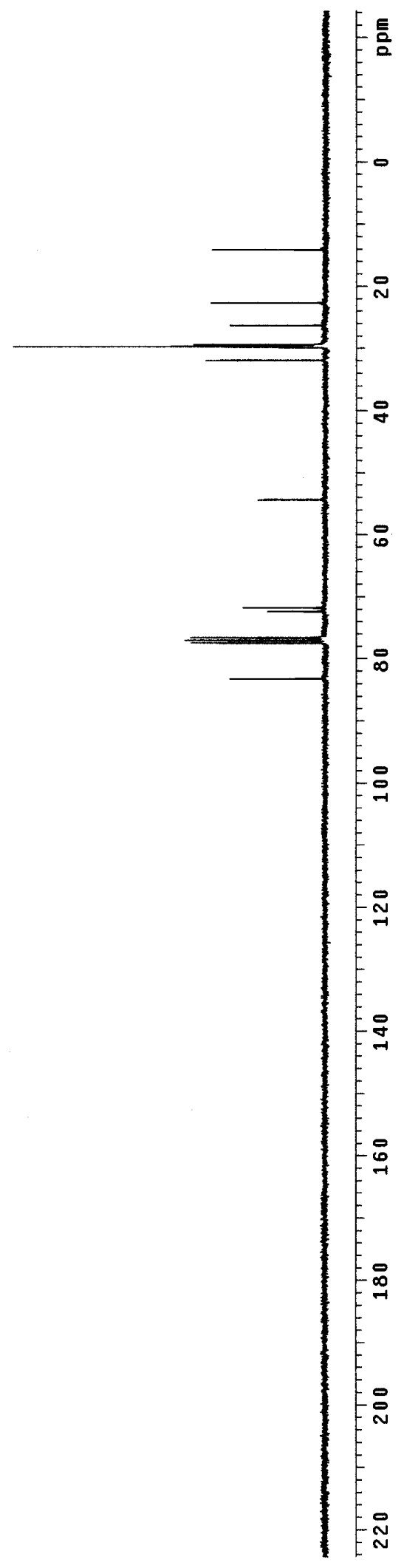




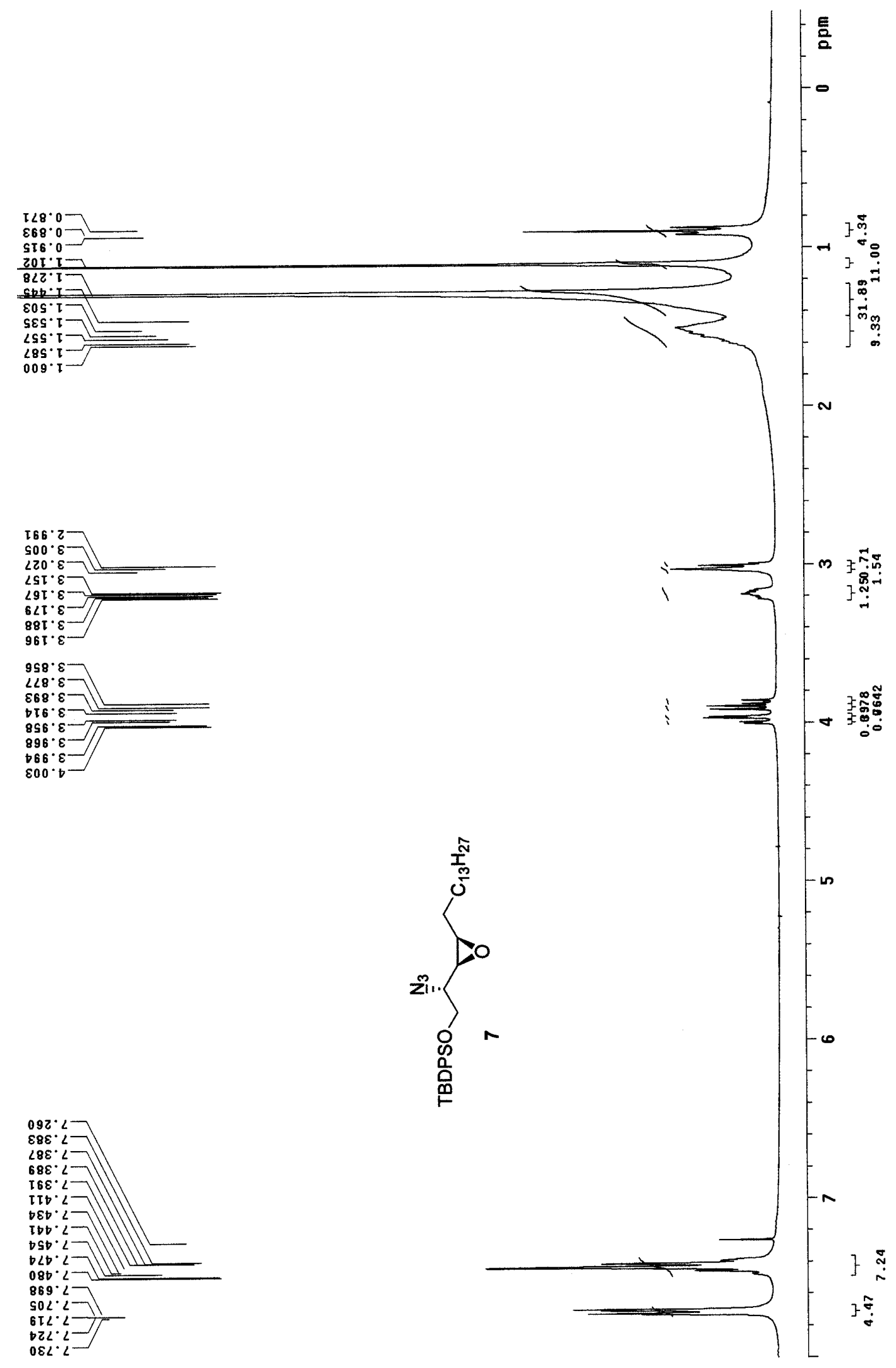



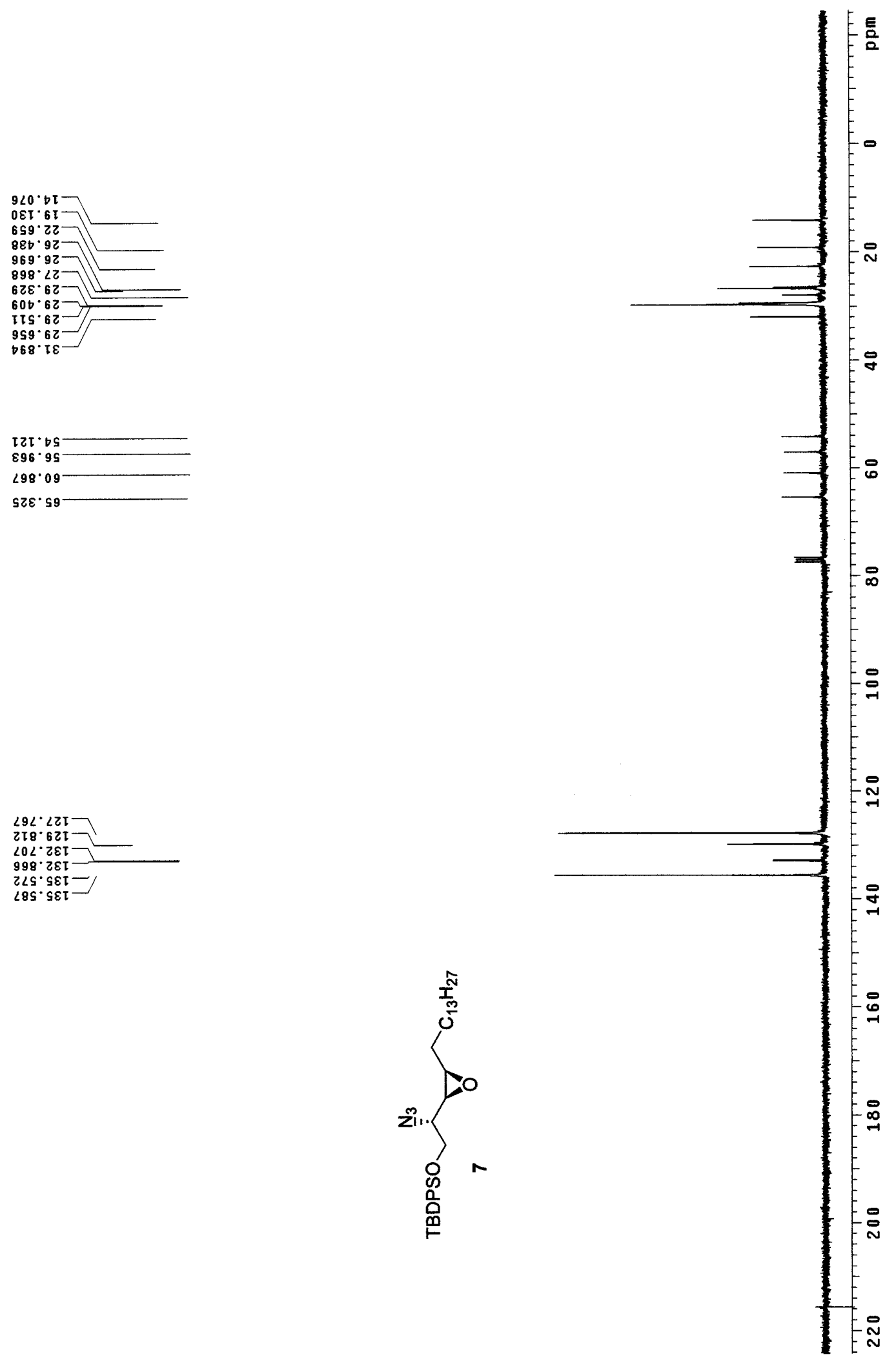


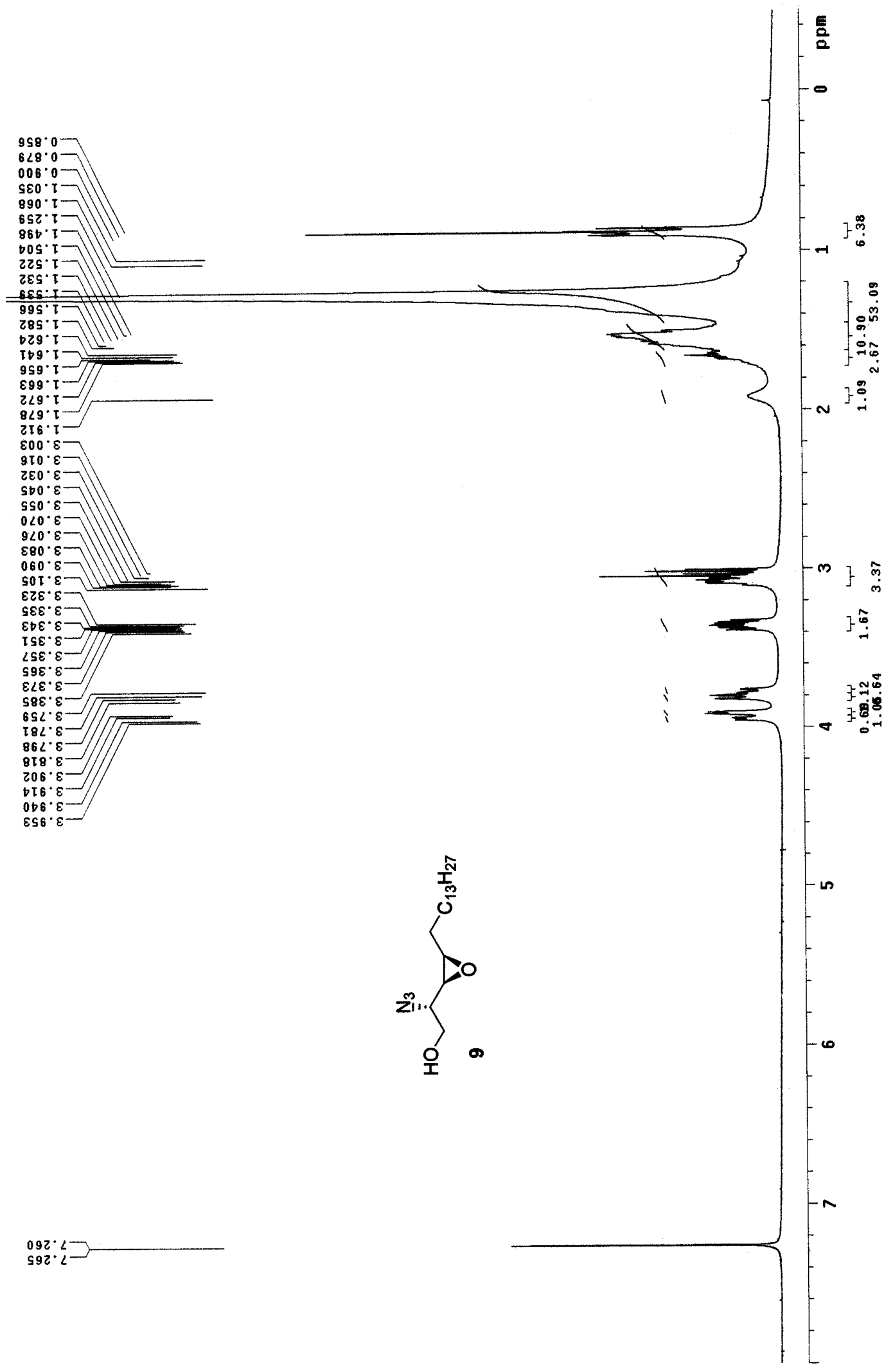



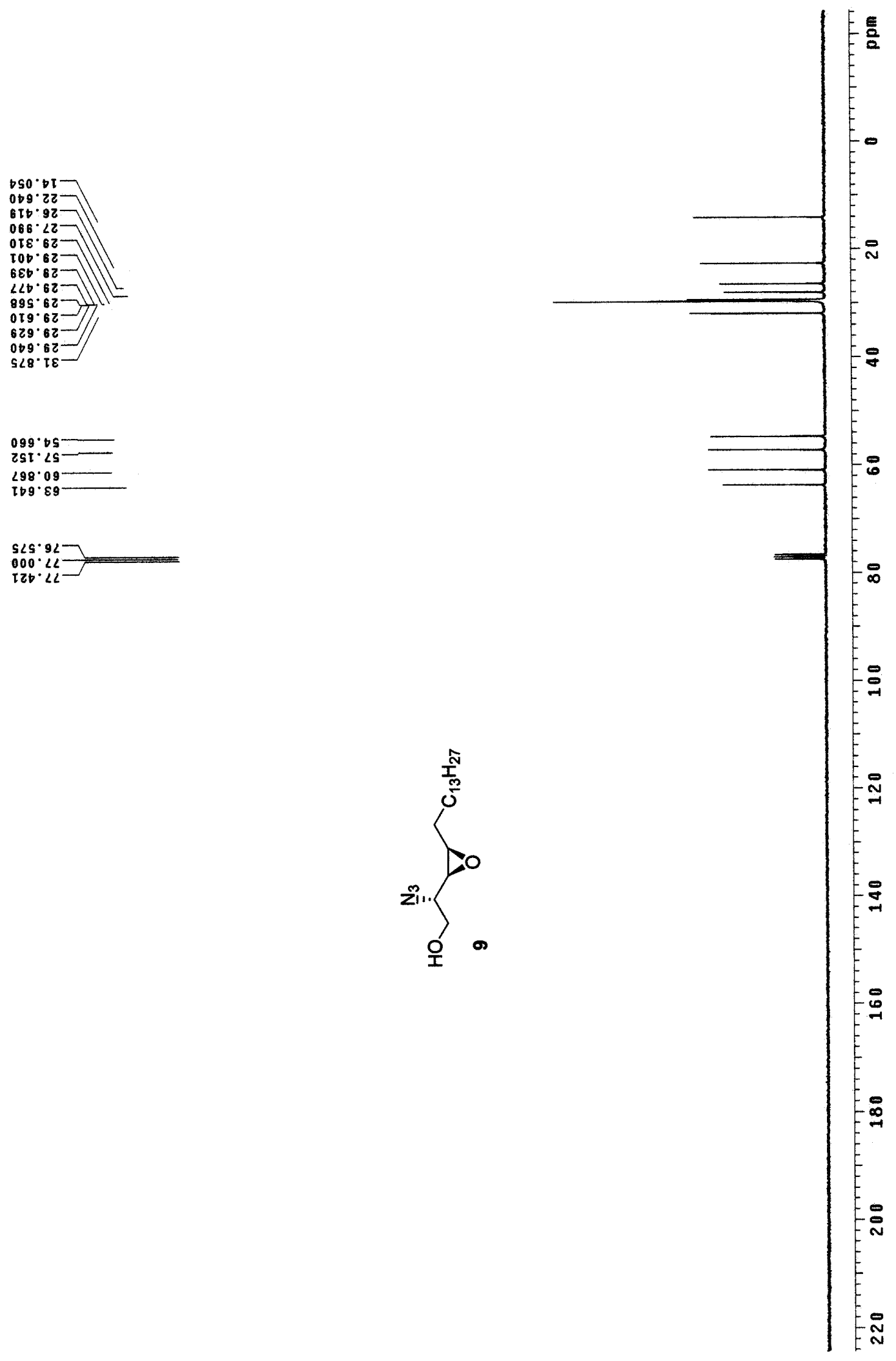


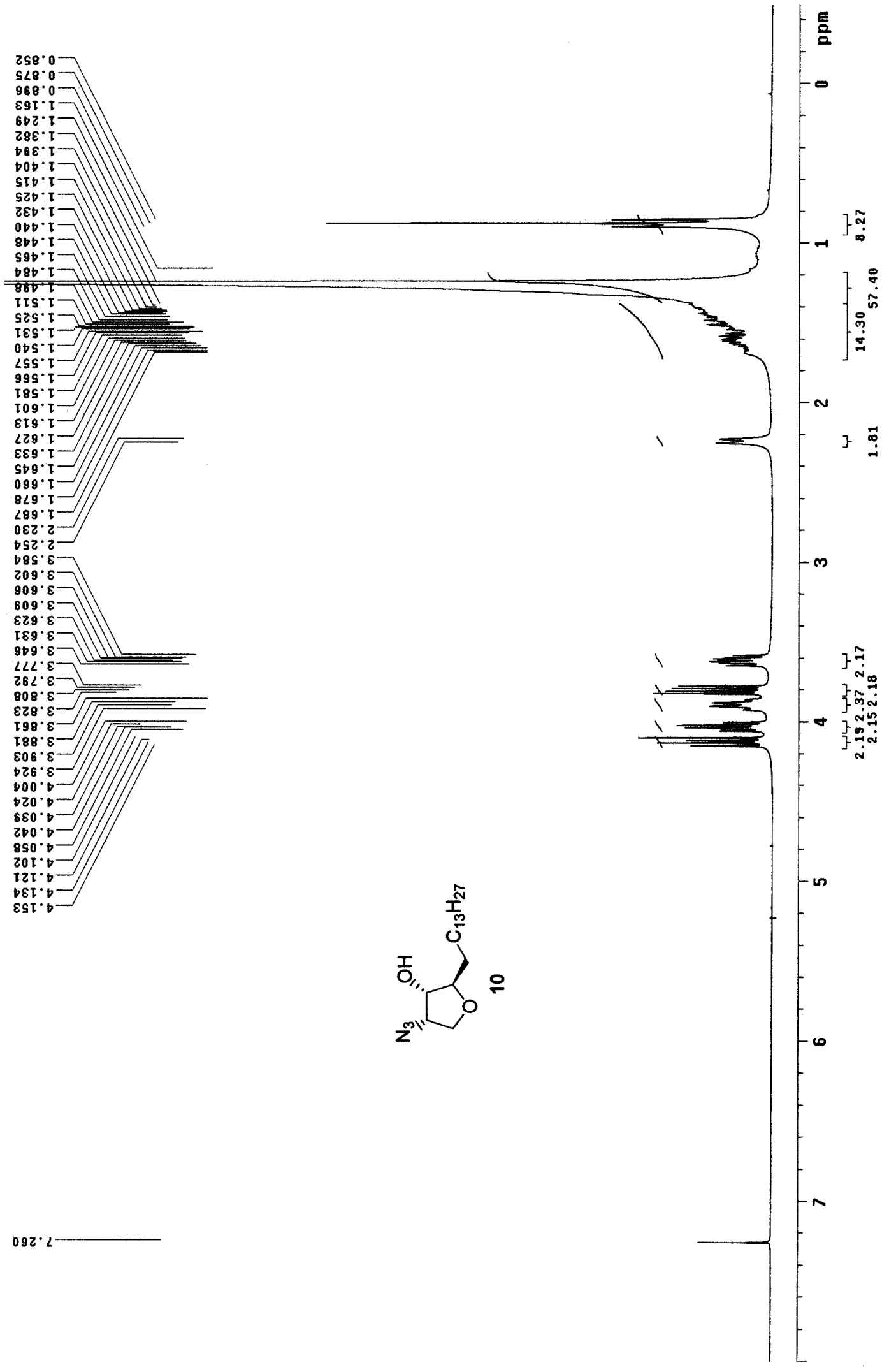



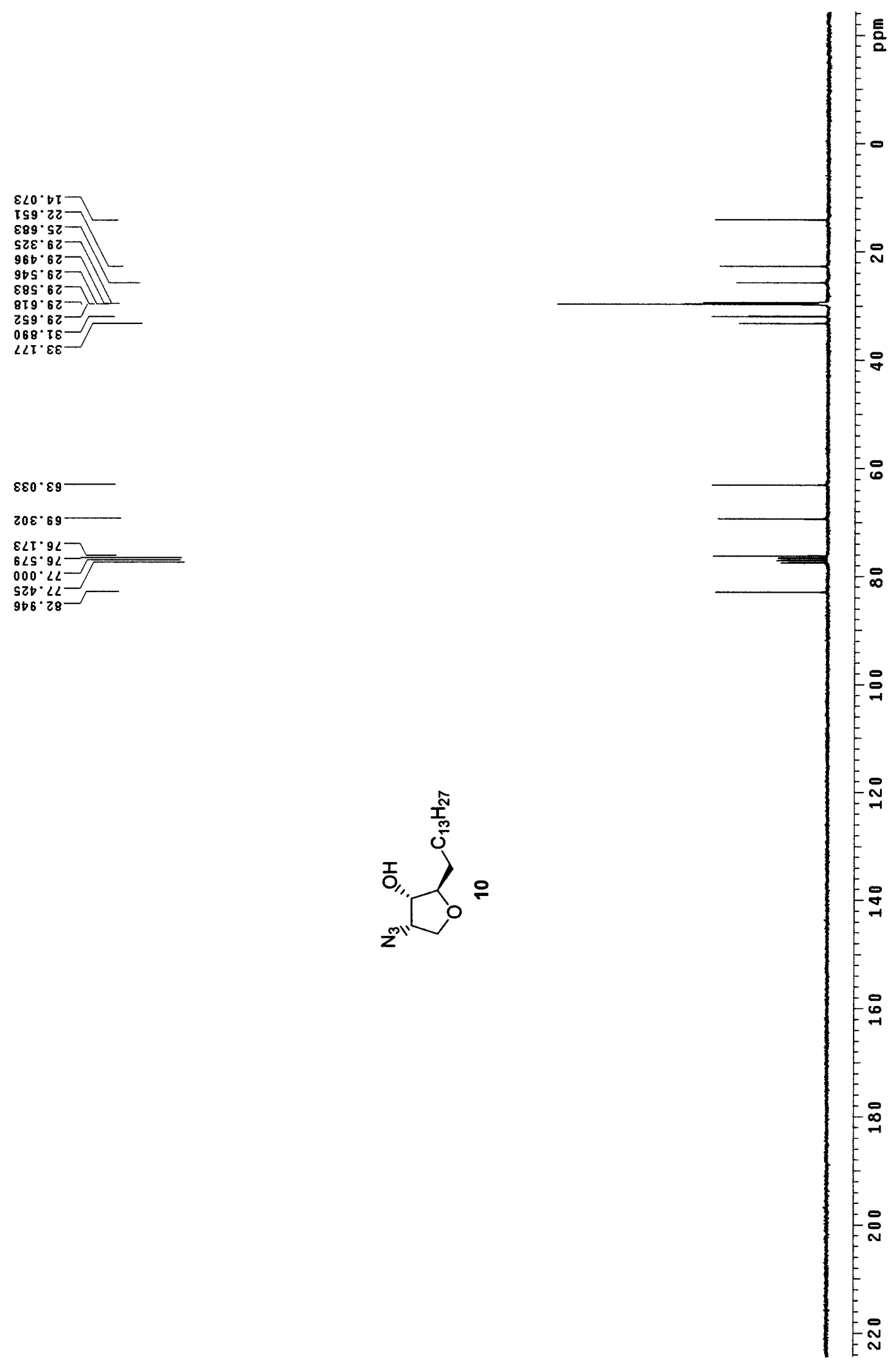


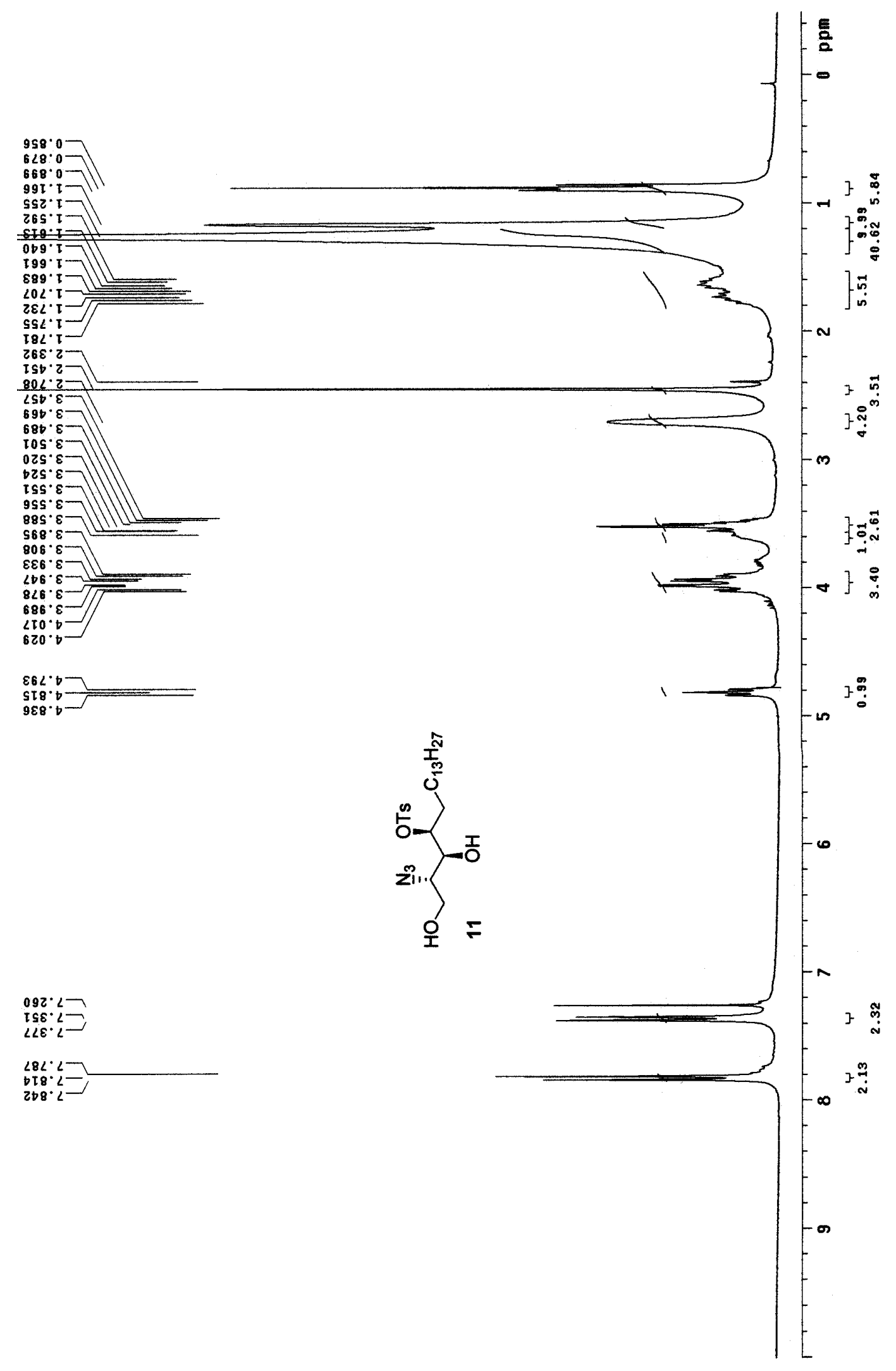




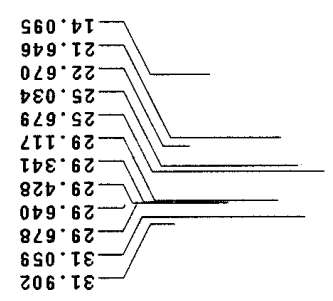

t5S. 29

$268 \cdot 29$

$850 \cdot T L$

$6 \angle 5^{\circ} 92$

$892 \cdot 28$

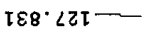

$268.62 I-$

$8 \angle 9 \cdot \varepsilon \varepsilon \tau$

$98 I \cdot S b I$

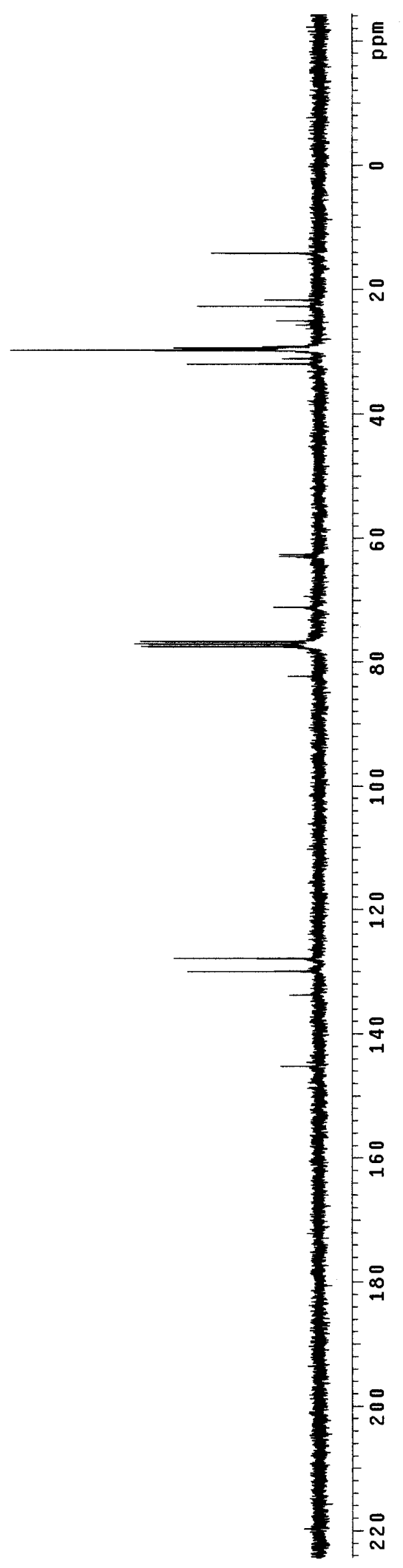




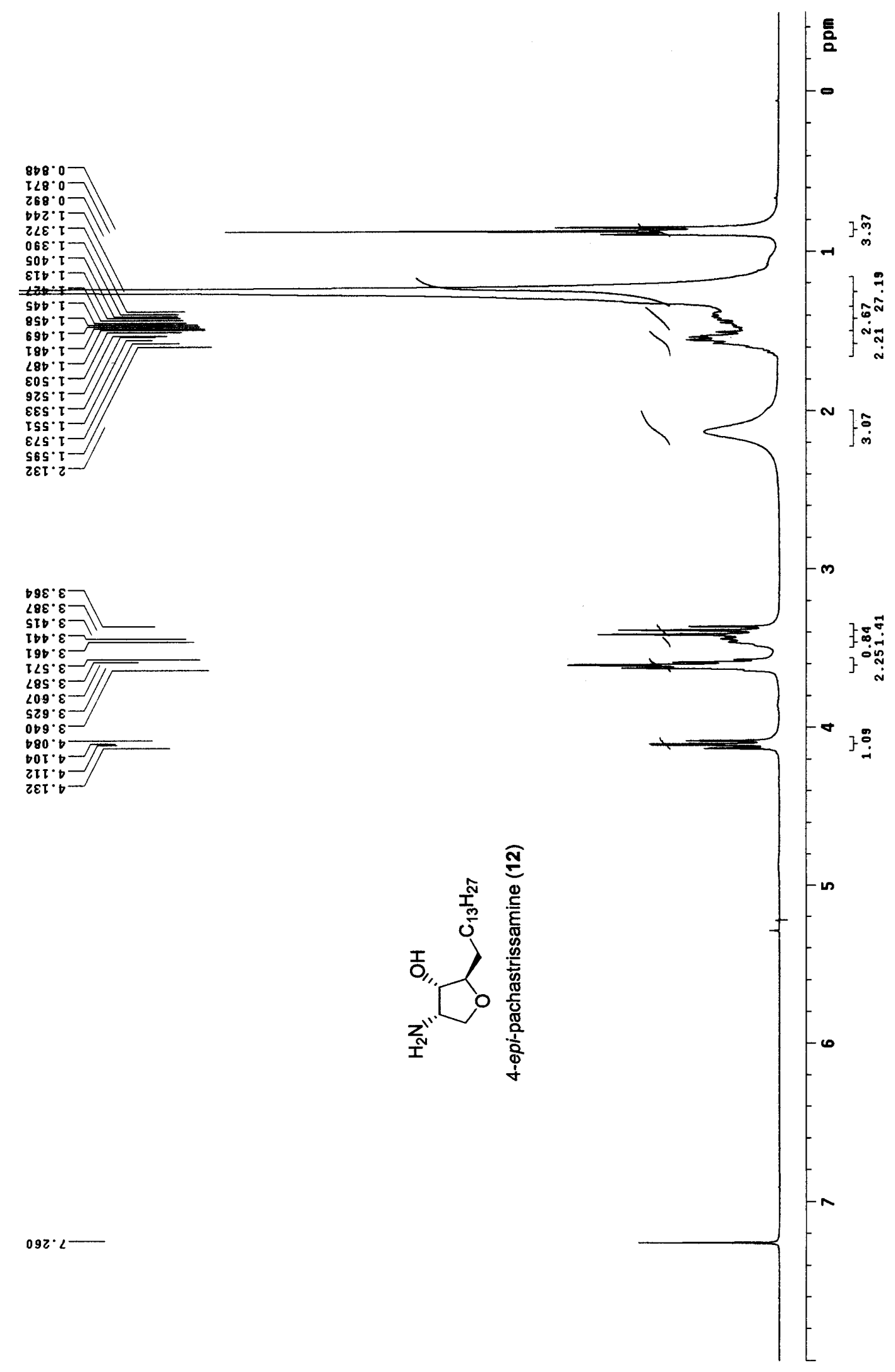




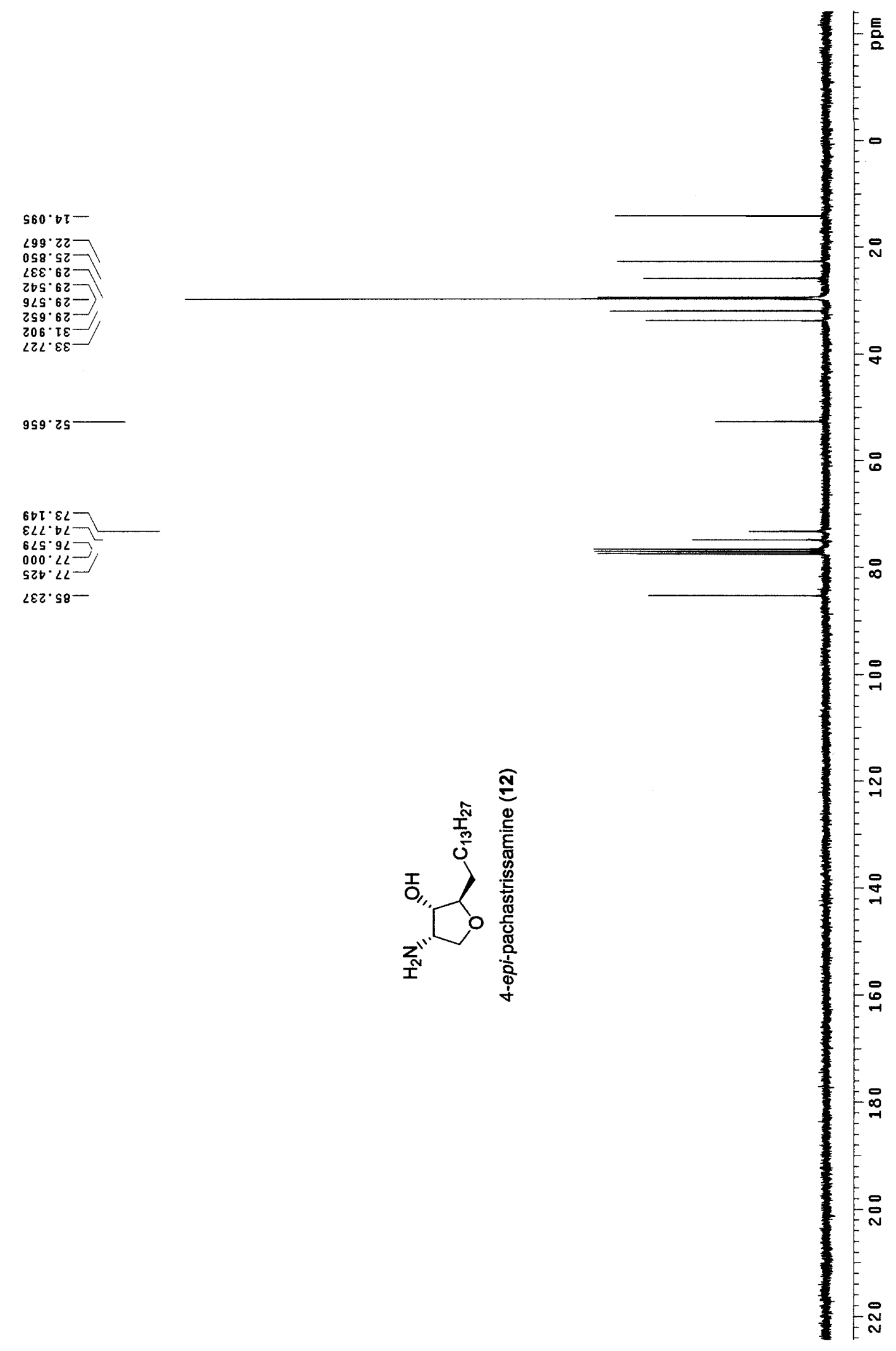

